IZA DP No. 4988

Market Imperfections and Firm-Sponsored Training

Matteo Picchio

Jan C. van Ours

June 2010 


\title{
Market Imperfections and Firm-Sponsored Training
}

\author{
Matteo Picchio \\ Tilburg University \\ and IZA \\ Jan C. van Ours \\ Tilburg University, CentER, \\ University of Melbourne, CEPR and IZA
}

\section{Discussion Paper No. 4988 \\ June 2010}

IZA

P.O. Box 7240

53072 Bonn

Germany

Phone: +49-228-3894-0

Fax: +49-228-3894-180

E-mail: iza@iza.org

\begin{abstract}
Any opinions expressed here are those of the author(s) and not those of IZA. Research published in this series may include views on policy, but the institute itself takes no institutional policy positions.

The Institute for the Study of Labor (IZA) in Bonn is a local and virtual international research center and a place of communication between science, politics and business. IZA is an independent nonprofit organization supported by Deutsche Post Foundation. The center is associated with the University of Bonn and offers a stimulating research environment through its international network, workshops and conferences, data service, project support, research visits and doctoral program. IZA engages in (i) original and internationally competitive research in all fields of labor economics, (ii) development of policy concepts, and (iii) dissemination of research results and concepts to the interested public.
\end{abstract}

IZA Discussion Papers often represent preliminary work and are circulated to encourage discussion. Citation of such a paper should account for its provisional character. A revised version may be available directly from the author. 
IZA Discussion Paper No. 4988

June 2010

\section{ABSTRACT}

\section{Market Imperfections and Firm-Sponsored Training*}

Recent human capital theories predict that labor market frictions and product market competition influence firm-sponsored training. Using matched worker-firm data from Dutch manufacturing, our paper empirically assesses the validity of these predictions. We find that a decrease in labor market frictions significantly reduces firms' training expenditures. Instead, product market competition does not have an effect on firm-sponsored training. We conclude that increasing competition through international integration and globalization does not pose a threat to investments in on-the-job training. An increase in labor market flexibility may reduce incentives of firms to invest in training, but the magnitude of this effect is small.

JEL Classification: $\quad$ D43, J24, J42, L22, M53

Keywords: firm-sponsored training, labor market frictions, product market competition, matched worker-firm data

Corresponding author:

Matteo Picchio

Department of Economics

Tilburg University

PO Box 90153

5000 LE Tilburg

The Netherlands

E-mail: m.picchio@uvt.nl

\footnotetext{
* We acknowledge financial support for this research by Stichting Instituut GAK, through Reflect, the Research Institute for Flexicurity, Labor Market Dynamics and Social Cohesion at Tilburg University. The estimates in this paper are based on own calculations using various micro datasets made available through a remote access facility by Statistics Netherlands.
} 


\section{Introduction}

On-the-job training of employed workers is important because a high-skilled labor force stimulates economic growth and facilitates sectoral adjustment of the economic structure. To the extent that investments in training of workers are good for labor market performance and economic growth, it is relevant to understand the main determinants of these investments. Firm-specific characteristics will influence training investments as firms may differ in their propensity to hire less skilled workers and invest in training of these workers or to hire more skilled workers and provide less training. And, there are also common determinants of firm-sponsored training related to market imperfections. An increase in competitiveness of the product market may affect training investments while more flexible labor market will also reduce investments in training.

Our paper focuses on the effects of labor market imperfections and product market competition on training. From a theoretical point of view the effect of market imperfections can go either way. More competition in the product market may reduce training because profits and investment funds go down, but it may also increase training if a better skilled workforce makes the firm more able to compete with other firms. Similarly, the effect of labor market competition can go either way. A higher labor mobility may increase the need for training but may at the same time reduce the willingness of firms to make the investment in training because with a shorter job tenure the pay-back period is reduced. If market imperfections influence firm-sponsored training, training subsidies or regulation may be justified on the basis of wellfounded arguments. Firm-sponsored training stimulates human capital accumulation and thus has a positive impact on productivity.

As discussed in more detail in the next section, previous empirical research on firm-sponsored training focuses on the effects on wages and productivity. So far, the effects of institutions, including labor market frictions and product market competition, have not received a lot of attention. Yet, in a changing economic environment in which labor markets have a tendency to become more flexible and product markets have a tendency to become more competitive through a process of international integration and globalization, these relationships are very policy relevant. Our paper focuses on the question how firm-sponsored training is influenced by labor market frictions and product market competition.

Our empirical analysis is based on Dutch matched worker-firm data. The worker data are informative on individual wages and labor market transitions by which we estimate the degree of labor market frictions. The firm data are informative on firms' revenues and costs by which we estimate a product market power index. The estimation strategy to identify the impact of these indexes on firm-sponsored training exploits their variation across markets and over time. We use econometric techniques that control for firm unobserved heterogeneity and we perform robustness check to test whether the results might be biased by too strict parametric assumptions. We find that a decrease in labor market frictions significantly reduces firms' training expenditures. Instead, product market competition does not have an effect on firm-sponsored training. From 
this we conclude that competition policy and increasing international competition will not pose adverse effects on firm-sponsored training of workers. An increase in labor market flexibility will lead to a lower training incidence. However, the size of this effect is rather small compared to the cross-sectional variation in the incidence of training.

Our paper is organized as follows. Section 2 reviews the related literature. The data are described in Section 3. Section 4 presents the indexes of market imperfections we use to test non-competitive training theories. The econometric model and estimation results are presented and discussed in Section 5. Section 6 concludes.

\section{Previous studies}

Becker's (1962) seminal paper on investment in human capital distinguishes two types of onthe-job training: specific and general. The former is useful only with the current employer, whereas the latter can be exploited also with other employers. Under the assumption of perfectly competitive labor and product markets, Becker $(1962,1964)$ shows that firms are unwilling to finance general training. Indeed, since workers are perfectly mobile and general human capital increases workers' productivity even at other employers, the current employer investing in general training will not be able to reap any of the future rents. Since workers have the right incentive to invest in their own general training, they will pay the cost and choose the first-best level of training.

There is however empirical evidence emphasizing that, although many training programs are general (Harhoff and Kane, 1997; Acemoglu and Pischke, 1999a; Loewenstein and Spletzer, 1999), employers sponsor them (Loewenstein and Spletzer, 1998; Barron et al., 1999; Green et al., 2000; Autor, 2001; Booth and Bryan, 2005). Hence, why do firms bear most of the costs of training? This question has inspired new theoretical models of training that depart from the Beckerian assumption of perfectly competitive markets. As originally pointed out by Becker (1962) and then by Acemoglu and Pischke (1999a,b), in case of labor market imperfections all the forms of training might be turned into being de facto specific. In words, as soon as firms have, for instance, some oligopsonistic power, workers are not paid their full marginal product when they change job and current employers can reap some rents. If training raises workers' productivity by more than wages (wage compression), employers have incentives to sponsor general training because it is profitable to do so.

Non-competitive theories of training have highlighted different sources of labor market imperfections leading to wage compression and firm-sponsored training. ${ }^{1}$ First, there might be search frictions, so that it is difficult for workers to quit and find a new suitable job (Acemoglu, 1997). ${ }^{2}$ If an employee takes time to find a new job that rewards her general training, the current

\footnotetext{
${ }^{1}$ See Leuven (2005) for a detailed survey of the theoretical sources of imperfect competition leading to wage compression and firm-sponsored training.

${ }^{2}$ See also Shintoyo (2008) for a search and matching model with firms that create job vacancies and are willing
} 
employer can momentarily extract rents from the worker and recoup the training investment. A second source of labor market imperfections is the presence of asymmetric information between the current employer of the worker and other firms. The information asymmetries might be about the amount of training the worker has acquired with the current employer (Katz and Ziderman, 1990; Chang and Wang, 1996) and/or about workers' ability (Chang and Wang, 1995; Acemoglu and Pischke, 1998). Potential future employers might be unwilling to pay workers for ex ante unverifiable productivity. This generates ex post informational monopsony power and makes it profitable for the current employer to sponsor general training. According to Manning (2003) a perfectly competitive labor market is likely to deliver an efficient level of training as no potential future employers of a worker can expect to make profits on them. However, also a very monopsonistic labor market will deliver an efficient level of training as there are few future employers to make profits out of the trained worker. Stevens (2001) indicates two main theoretical reasons for failure in the training market. The first is the limited access to capital markets which prohibits workers to borrow against human capital. The reason for market failure is imperfect competition in the labor market which may lead to underinvestment.

Firm-sponsored training may also be influenced by competition in the product market. Gersbach and Schmutzler (2006) designed a model characterized by a three-stage game and oligopolistic product market competition. In the first stage firms decide how many workers are to be trained. In the second stage firms make wage offers to trained employees and workers accept the best offer. In the last stage, firms engage in oligopolistic product market competition. Under the assumption that training increases employees' productivity, an additional trained worker in the own firm increases the own productivity and weakens the competitor. Considering that a reduction in training activities results in an increase in trained workers' wages, firm-sponsored training arises as an equilibrium outcome since firms prefer to train workers to keep lower ex-post wages, rather than paying higher wages to poach them from the competitors. Gersbach and Schmutzler (2006) argue that the softer the competition, the higher the training incentives since poaching is more costly. However, Brunello and De Paola (2008) show that the relationship between product market competition and training can be ambiguous: if an increase in competition affects the proximity of workers and firms, the negative effect of poaching on training can be compensated by positive local agglomeration effects.

Few studies have attempted to directly test the predictions of non-competitive models of training. Autor (2001) focuses on temporary help supply firms in the US, finding that firmprovided training increases with product market competition. Bassanini and Brunello (2010) examine 15 European countries and 12 industries finding that an increase in product market deregulation generates a sizeable increase in training incidence. Görlitz and Stiebale (2008) find instead no significant effect of competition measures on training in Germany. Muehlemann and Wolter (2007) and Muehlemann (2008) find that Swiss firms are less likely to provide apprenticeship training in dense regional labor markets, where the probability that workers are

to sponsor general training. 
poached by other firms is higher. Brunello and Gambarotto (2007) find that in the UK firmsponsored training is less frequent in areas with higher local employment density.

Bassanini and Brunello (2008) find that training is more frequent when the wage premium is smaller; they argue that this result contrasts with Beckerian predictions but is not inconsistent with training models with frictional labor markets. The aforementioned non-competitive models of training assume that the difference between productivity and wages is increasing with training: this is confirmed by the empirical evidence in Gerfin (2004). Barron et al. (1999) find a large impact of training on firm's productivity growth and an extremely small impact of training on wages. They claim that this suggests that firms pay most of the cost and reap most of the returns to training. Finally, Acemoglu and Pischke (1998) empirically tested some implications of their theoretical training model with asymmetric information, finding support from the data.

\section{$3 \quad$ Firm-sponsored training}

The data we use in our empirical investigation are gathered by Statistics Netherlands at the level of both workers and firms. We use information about firm-sponsored training at the level of firms, i.e. whether or not firms participated in training of their workers, and if so how much money was spent on this. ${ }^{3}$ The firm data are also used both to compute the product market competition index at the 3-digit SIC industry level and to infer its impact on firm-sponsored training. The firm data come from the 2000-2005 waves of the Industry Production Survey (PS). All the Dutch manufacturing firms with 20 or more employees are in the PS data. Units smaller than 20 employees are instead representatively drawn from the corresponding census population. We focus on firms larger than 20 employees. About 7,000 such firms are surveyed each year, which results in about 35,000 observations in the period 2001-2005. We lose indeed one time period, as the market imperfection indexes enter the reduced form model for training with a lag of order one. We deleted observations with missing values for some variables used in the econometric analysis and we retained firms with multiple time observations. This results in a unbalanced panel made up of 26,707 observations for the time period 2001-2005, corresponding to 6,647 different firms. Appendix A provides more details on our data, including sample characteristics.

Table 1 reports descriptive statistics on firm-sponsored training by year over the timewindow used in the econometric analysis. The fraction of firms providing training to their employees has monotonically decreased from 2001 until 2005, going from more than $76 \%$ in 2001 to $57.7 \%$ in 2005 . The average expenditure on training has displayed a similar pattern over time, from $€ 260$ in 2001 to $€ 207$ in 2005 per unit of labor. The decreasing profile of training investments is however essentially related to the decline in the fraction of firms investing in training. If we look at the expenditure in training conditional on sponsoring training, we can

\footnotetext{
${ }^{3}$ Statistics Netherlands reports statistical information on training of workers only on a irregular basis. The two most recent surveys on firm-sponsored training are from 1999 and 2005.
} 
Table 1: Sample characteristics and summary statistics, 2000-2005

\begin{tabular}{|c|c|c|c|c|c|c|c|c|}
\hline & \multirow{2}{*}{\multicolumn{2}{|c|}{$\begin{array}{c}\text { Firm data } \\
\text { Training }\end{array}$}} & \multicolumn{2}{|c|}{ Worker data } & \multicolumn{4}{|c|}{ Industry data } \\
\hline & & & \multirow{2}{*}{$\begin{array}{c}\text { Gross } \\
\text { hourly } \\
\text { wage (€) }\end{array}$} & \multirow{2}{*}{$\begin{array}{c}\text { Elapsed job } \\
\text { duration } \\
\text { (years) }\end{array}$} & \multicolumn{3}{|c|}{ Labor market frictions } & \multirow{2}{*}{$\begin{array}{c}\text { Profit } \\
\text { elasticity }\end{array}$} \\
\hline & $\begin{array}{c}\text { Fraction } \\
(\%)\end{array}$ & $\begin{array}{c}\text { Expenditures } \\
(€)\end{array}$ & & & $\phi$ & $\begin{array}{c}\lambda \\
* 0.01\end{array}$ & $\begin{array}{c}\delta \\
* 0.01\end{array}$ & \\
\hline 2000 & - & - & 15.89 & 12.6 & 0.4 & 0.94 & 0.47 & 7.53 \\
\hline 2001 & 76.2 & 260 & 15.85 & 12.6 & 0.39 & 0.93 & 0.48 & 7.52 \\
\hline 2002 & 66.0 & 237 & 15.81 & 12.7 & 0.41 & 0.97 & 0.48 & 7.71 \\
\hline 2003 & 62.6 & 213 & 15.97 & 12.7 & 0.44 & 0.96 & 0.48 & 7.89 \\
\hline 2004 & 59.6 & 194 & 16.08 & 12.8 & 0.47 & 0.84 & 0.49 & 7.82 \\
\hline 2005 & 57.7 & 207 & 16.09 & 13.1 & 0.51 & 0.72 & 0.49 & 8.48 \\
\hline Overall & 63.5 & 220 & 15.95 & 12.8 & 0.44 & 0.89 & 0.48 & 7.82 \\
\hline Std.Dev. & 48.1 & 470 & 6.52 & 10.4 & 0.22 & 0.71 & 0.13 & 5.87 \\
\hline Minimum & 0 & 0 & 6.52 & 0.0 & 0.02 & 0 & 0.28 & 0.69 \\
\hline Maximum & 100 & 25350 & 46.33 & 51.2 & 1 & 17.71 & 2.28 & 66.7 \\
\hline Observations & \multicolumn{2}{|c|}{26,707} & \multicolumn{2}{|c|}{$2,327,036$} & \multicolumn{4}{|c|}{492} \\
\hline
\end{tabular}

Note: Hourly gross wages are in real terms in 2005 prices (CPI in 2005=100); Labor market frictions: $\phi=$ index, $\lambda=$ monthly job offer arrival rate, $\delta=$ monthly job destruction rate.

Table 2: Characteristics firm-sponsored training

\begin{tabular}{rrrcc}
\hline \hline Variables - Quartiles & $0-25$ & $25-50$ & $50-75$ & $75-100$ \\
\hline Number of employees & {$[20-35]$} & $(35-54]$ & $(54-108]$ & $>108$ \\
Fraction of firms sponsoring training $(\%)$ & 49.6 & 55.1 & 65.9 & 84.7 \\
Expenditure on training per unit of labor $(€)$ & 150 & 166 & 217 & 349 \\
\hline & & & & \\
Temporary work agency costs $(€ 1,000)$ & {$[0-1]$} & $(1-66]$ & $(66-315]$ & $>315$ \\
Fraction of firms sponsoring training (\%) & 72.5 & 64.7 & 68.6 & 79.3 \\
Expenditure on training per unit of labor $(€)$ & 209 & 186 & 233 & 324 \\
\hline$R \& D(€ 1000)$ & & & & \\
Fraction of firms sponsoring training $(\%)$ & 57.2 & 75.7 & $>3$ \\
Expenditure on training per unit of labor $(€)$ & 187 & 159 & 325 \\
\hline
\end{tabular}

Note: Average 2001-2005.

see a different scenario: the conditional average expenditure in training has slightly increased over time, going from $€ 340$ in 2001 to $€ 360$ in 2005.

Table 2 provides some characteristics of firm-sponsored training in our sample. As said, participation in training increases with firm size from $49.6 \%$ in small firms to $84.7 \%$ in large firms; expenditures show a similar pattern. Firm-sponsored training does not seem to be correlated with expenditures on temporary work agencies, while there is positive relationship between expenditures on R\&D and firm-sponsored training. Whereas $57.2 \%$ of firms with no R\&D expenditures participates in training, $80.5 \%$ of the firms with more than $€ 3000$ R\&D expenditures participates in training. This suggests some complementarities between R\&D and employers' propensity to invest in training.

The labor market friction index is based on worker data, which are from the 2000-2005 
waves of the SSB Jobs (Social Statistical Database of Jobs). They contain information on all the employees working in the Netherlands including sector, job starting and termination dates, monthly wage, and working hours. Since the paper focuses on manufacturing firms, we retained only employees that in each cross-section work in the manufacturing industry. Then, we retained individuals between 15 and 65 years of age and we deleted observations lying in the first and last percentiles of the wage or working hour distributions. We end up with yearly cross-sections of about 340,000-400,000 individuals each. Concise summary statistics on hourly wages and job durations are reported in Table 1 . Real hourly wages do not change much over time, while average job duration does not show much variation either. Appendix B-1 clarifies in detail how we exploit the information on wages and job durations to estimate the labor market friction index, also reported in Table 1.

\section{Market imperfections}

This paper is aimed at understanding the effect of market imperfections on firm-sponsored training. We define both labor market and product market on the level of the 3-digit SIC industry classification. Whereas for product markets the industry classification is rather straightforward, for labor markets the issue of market definition is more complex. One practical reason for our choice is that the labor market definition should be such that it is possible to match the estimated measure from worker data with firm data: the firm data we have can only be stratified according to industry and not according to occupation, education, or area of residence. ${ }^{4}$

In order to approximate labor market imperfections, we estimate an index of labor market frictions based on the rate at which job opportunities arise as a fraction of the rate at which they are needed. ${ }^{5}$ If $\lambda$ is the employees' job offer arrival rate and $\delta$ is the job destruction rate, the frictional indicator $\phi$ is defined as

$$
\phi \equiv \frac{\delta}{\delta+\lambda},
$$

and takes therefore value on $[0,1]$. If no jobs are destroyed there are no labor market frictions; if no job offers arrive there are maximum frictions in the labor market. The frictional index is supposed to capture those mobility costs, information asymmetries, institutions, product market turbulence, and labor market congestions that make difficult or unlikely for a worker to move to another job or to receive interesting wage offers from other firms. Hence, the higher the value of frictional index $\phi$ in a market, the higher firms' willingness to sponsor training.

The labor market friction parameters are estimated separately per each 3-digit manufactur-

\footnotetext{
${ }^{4}$ Moreover, our simplifying assumption for the operational definition of labor market is consistent with the fact that workers more often stay within the same sector than, for instance, within the same occupation (Bontemps et al., 2000).

${ }^{5}$ This labor market friction index has been proposed by Ridder and van den Berg (2003). See also van den Berg and van Vuuren (2005) for an empirical application.
} 
ing sector and per each time period of the window 2000-2005. Columns 5 to 7 of Table 1 reports the corresponding summary statistics (the details of estimation procedure are presented in Appendix B-1). The monthly job offer arrival rate $\lambda$ increases until 2002, when it reaches its maximum average value (0.0097), and then declines gradually up to 0.0072 in 2005 . The monthly job destruction rate $\delta$ does not display much time-variation on average and ranges between 0.0047 and 0.0049 . The frictional index $\phi$ is almost monotonically increasing over the period under study and reveals that, in the manufacturing industry, the average labor market friction has increased, going from about 0.40 in 2000 up to 0.51 in 2005.

There is substantial variation in $\phi$ over time and across sectors. The scatter diagrams in the top of Figure 1 show the cross-sector variation by plotting the fraction of firms investing in training (left panel) or the average expenditure on training (right panel) in each 3-digit sector and the average labor market friction. There is a lot of variation in both the labor market friction index as well as in the investments in training. However, no clear pattern between firm-sponsored training and labor market frictions seems to emerge from raw data and across sectors.

The indicator for product market competition is also estimated separately per each 3-digit manufacturing sector and per each time period of the window 2000-2005. The product market competition index used in this paper is the one proposed by Boone et al. (2009): the profit elasticity (PE). In words, $\mathrm{PE}$ is the percentage variation in profits due to a percentage increase in marginal costs. The last column of Table 1 reports the corresponding summary statistics (the details of estimation procedure are presented in Appendix B-2). We find that, overall, PE is of about 7.8 on average: a $1 \%$ increase in costs leads to a $7.8 \%$ reduction in profits. This is very much in line with the estimation results in Boone et al. (2009). It can also be noted that PE has increased over time, meaning that in the Netherlands competition in manufacturing has become tougher on average. There is substantial variation in PE. There are sectors where the PE is lower than 1 and sectors in which profits are more than halved by a one percent increase in costs. As for the estimates of the labor market friction index, the bottom graphs of Figure 1 shows no discernible pattern across sectors between firm-sponsored training and profit elasticity. ${ }^{6}$

The market imperfections measures estimated in this section point out that in the period 2000-2005 the Dutch manufacturing industry has become more competitive on the product market side and characterized by an higher degree of frictions on the labor market side. This is a scenario that is compatible, for example, with the case in which the domestic product competition has become tougher, maybe because of less strict barrier policies, whilst labor market friction has increased as a consequence of the exits of the least efficient firms (lower job offer arrival rate and higher job destruction rate). The correlation between the product market competition indicator and the index for labor market frictions is weak, about 0.19 . The scatter

\footnotetext{
${ }^{6}$ There is a lot of variation in the profit elasticity with clear outliers. In a sensitivity analysis we will investigate whether it matters to exclude the outliers.
} 
Figure 1: Market imperfections and Firm-Sponsored Training across 3-digit SIC industries

a. Labor market frictions $-\phi$

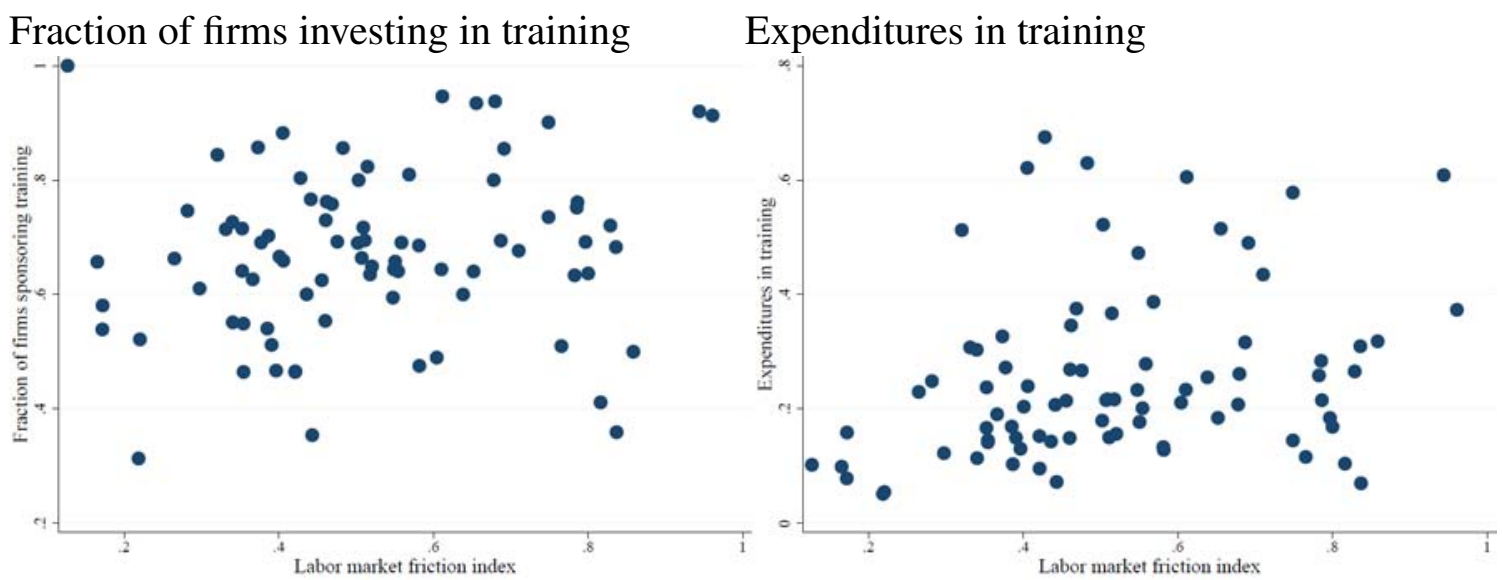

b. Product market competition - PE

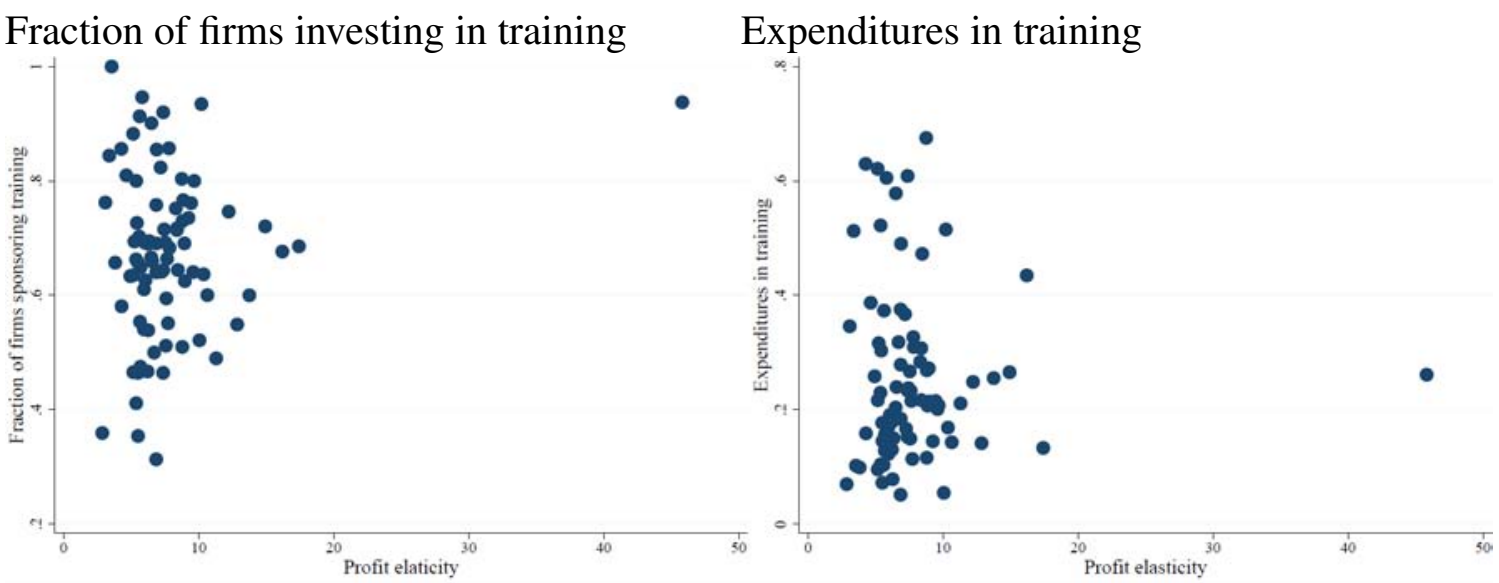


Figure 2: Product market competition and labor market frictions

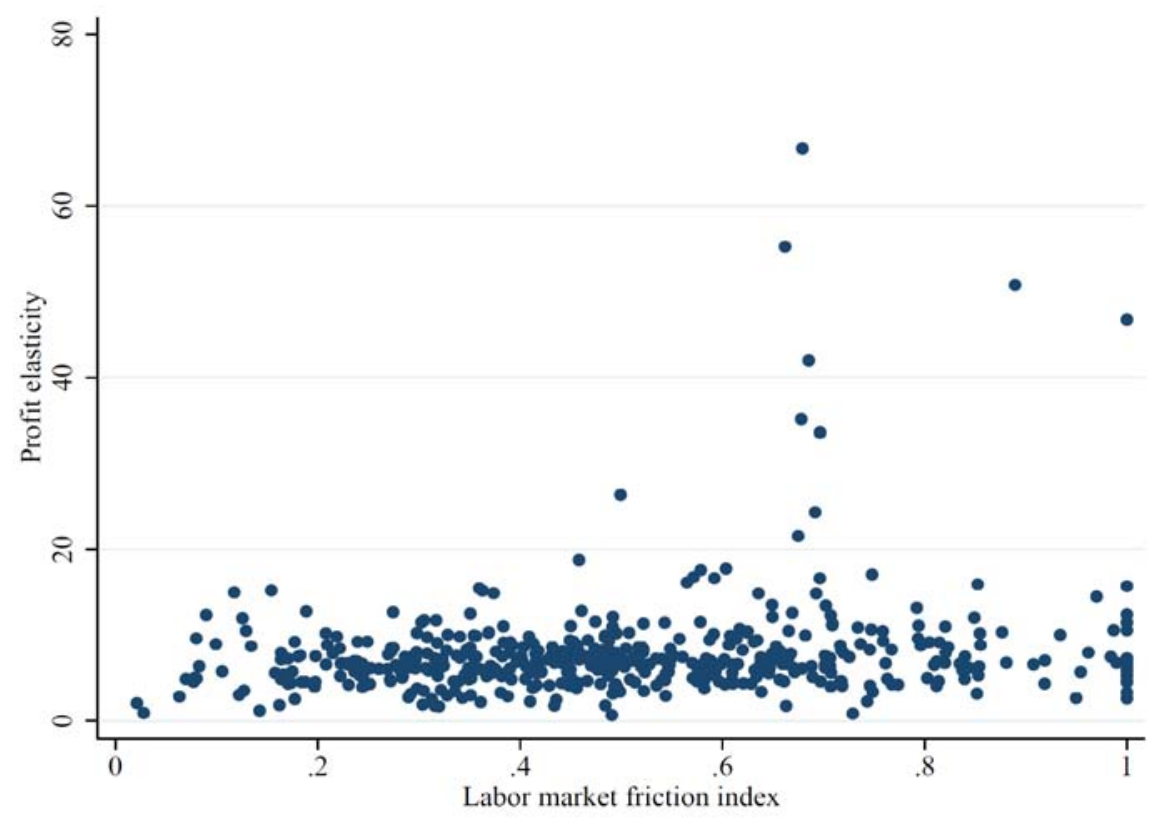

plot in Figure 2 shows indeed no particular relationship between the two indicators. ${ }^{7}$

\section{Econometric modeling and estimation results}

\subsection{Our model}

As discussed in Section 3, a large part of the firms in our sample do not sponsor training. Hence, our dependent variable is partly continuous with a positive and large probability mass at zero investments in training. When modeling such a response variable, it has to be taken into account the presence of a corner solution outcome. Usual linear estimators are indeed generally inconsistent if applied either to the entire sample or to the sample for which the outcome variable is strictly positive.

Denote by $y_{i t}$ firm $i$ 's investment in training per unit of labor at time $t$. The corner solution outcome regression model for panel data with firm unobserved effects is

$$
\begin{aligned}
& y_{i t}^{*}=x_{i t}^{\prime} \beta+c_{i}+c_{t}+u_{i t}, \quad i=1, \ldots, N, \quad t=1, \ldots, T \\
& y_{i t}=\max \left(0, y_{i t}^{*}\right),
\end{aligned}
$$

\footnotetext{
${ }^{7}$ Other factors might explain the time-variation of the labor market frictions index: e.g. ignorance among workers about labor market opportunities, individual heterogeneity in preferences over jobs, and mobility costs (Manning, 2003, § 13.1).
} 
where $x_{i t}$ is a set of firm characteristics controlling for firm heterogeneity and including the market imperfection indexes (stratified at 3-digit SIC industry level), $c_{i}$ is the firm effect, $c_{t}$ is the calendar year effect, $u_{i t}$ is the error term, and $\beta$ is the vector of unknown parameters. The calendar year effects are included to account for cyclical variation in firm-sponsored training, which may be due to variation in resources or labor turnover. In recession firms may face tighter resources, and in recessions there is less worker mobility and therefore less need for training of new workers. The market imperfection index enters the training equation with a lag of order one. We are implicitly assuming that the timing of events is as follows: i) first, the firm management observes the situation and the development of the market during the current year; ii) second, it reacts accordingly by planning the workforce training investment for the next period. $^{8}$

From the data we observe $\left(y_{i t}, x_{i t}\right)$. In the benchmark model we impose parametric assumptions on the distributions of $c_{i}$ and $u_{i t}$. The former is such that it allows for dependence between $c_{i}$ and $x_{i}=\left(x_{i 1}^{\prime}, \ldots, x_{i T}^{\prime}\right)^{\prime}$. More in detail, we use a Mundlak (1978) version of Chamberlain's (1984) approach. Correlation between $c_{i}$ and $x_{i}$ is allowed by adopting a correlated random-effects specification:

$$
\begin{aligned}
c_{i} & =\alpha+\bar{x}_{i}^{\prime} \xi+a_{i}, \\
a_{i} \mid x_{i} & \sim \mathrm{N}\left(0, \sigma_{a}^{2}\right),
\end{aligned}
$$

where $\bar{x}_{i}$ is the time average of $x_{i t}$ and $\xi$ is an unknown vector of parameters. The error term $u_{i}$ is assumed to be normally distributed $\mathrm{N}(0, \Sigma)$ and independent on $\left(x_{i}, c_{i}\right)$. Then, model (2)-(3) can be rewritten as

$$
y_{i t}=\max \left(0, x_{i t}^{\prime} \beta+\alpha+\bar{x}_{i}^{\prime} \xi+a_{i}+c_{t}+u_{i t}\right)
$$

and estimated using a pooled tobit maximum likelihood approach to allow arbitrary serial correlation of the error term. ${ }^{9}$ Defining $v_{i t}=a_{i}+u_{i t}$, the log-likelihood function to be maximized is

$$
\begin{aligned}
\ln \mathscr{L}(\Theta) & =\sum_{i=1}^{N} \sum_{t=1}^{T}\left\{1\left(y_{i t}=0\right) \ln \left[1-\Phi\left(\frac{x_{i t}^{\prime} \beta+\alpha+c_{t}+\bar{x}_{i}^{\prime} \xi}{\sigma_{v}}\right)\right]\right. \\
& \left.+1\left(y_{i t}>0\right)\left[\ln \phi\left(\frac{y_{i t}-x_{i t}^{\prime} \beta-\alpha-c_{t}-\bar{x}_{i}^{\prime} \xi}{\sigma_{v}}\right)-\frac{\ln \left(\sigma_{v}^{2}\right)}{2}\right]\right\}
\end{aligned}
$$

where $\Theta=\left(\alpha, c_{t}, \beta^{\prime}, \xi^{\prime}, \sigma_{v}\right)^{\prime}$ is the parameter vector to be estimated and $\Phi$ and $\phi$ denote, respectively, the CDF and the PDF of the standard normal distribution.

\footnotetext{
${ }^{8}$ See Section 5.3 for a sensitivity analysis that is conducted by including among the regressors also the contemporaneous value of the market imperfection index. It yields that the strict exogeneity of the market imperfection indexes seems to be supported by the data.

${ }^{9}$ All the parameters will be then scaled by a factor $\left(1+\sigma_{a}^{2}\right)^{-1 / 2}$. Average partial effects will be however consistently estimated by the scaled parameters.
} 
The vector $x_{i t}$ contains, apart from the market imperfection indexes, a set of covariates aimed at controlling for observable heterogeneity at firm level that might be correlated to training intensity and to the sectoral market imperfection index. We try to use all the information in the dataset that could capture heterogeneous time variation of firm structure, organization, management, adoption of technical change, and productivity: value added, firm size, grants, sales, investments in machine and equipment, buildings and lands, $\mathrm{R} \& \mathrm{D}$, labor costs, expenditure on temporary work agencies, advertising costs, communication costs, patent costs, energy costs, industry indicators at 2-digit SIC level, and time dummies. ${ }^{10}$

\subsection{The estimation results}

Table 3 reports estimation results of the model in which both the labor market friction and the product market power indexes are included in the training equation. Columns (5) and (6) focus on the unobserved effects tobit model in equation (7) which is the benchmark estimation techniques. Columns (1) and (2) refer to a linear model that ignores both the presence of corner solutions and correlated random effects. Columns (3) and (4) refer to a pooled tobit model that ignores the presence of the correlated random effects.

Table 3 shows that the estimation results are similar across different estimation techniques. Moving from POLS to pooled tobit estimation, we take into account of the corner solution outcomes at the cost of imposing the normality assumption on the training intensity distribution. The effect of the labor market friction indicator is barely significant. If frictions increase by $10 \%$, the probability that firms sponsor some training increases by 0.4 percentage points and the investment intensity on training increases by $1.2 \%$. When the presence of correlated random effects is taken into account, we get effects of friction on firm-sponsored training that are significant at $5 \%$ and slightly bigger in size. A $10 \%$ increase in frictions generates a 0.5 percentage points increase of the probability of firms of deciding to invest in training and a $1.5 \%$ increase in training expenditures. Note that a Wald test for significance of the coefficients of the linear approximation of the firm unobserved heterogeneity largely rejects the null hypothesis. Performing the analysis without the time-average of the covariates would generate biased results due to their correlation with unobserved heterogeneity.

The effect of product market competition is small and insignificant. This result is in line with the findings in Görlitz and Stiebale (2008). They studied the impact of different measures of product market competition on the firm's number of trained employees in Germany. We used a more robust measure of product market competition and a finer measure of firms' investment in training. As in Görlitz and Stiebale (2008), we ended up however with results that does not strongly support the theoretical predictions of Gersbach and Schmutzler (2006).

\footnotetext{
${ }^{10}$ Banking costs, outsourcing costs, and profits were preliminary included as additional regressors, but, since always not significant, removed from the training equation.
} 
Table 3: Estimation results: the effect of market imperfections on firm-sponsored training

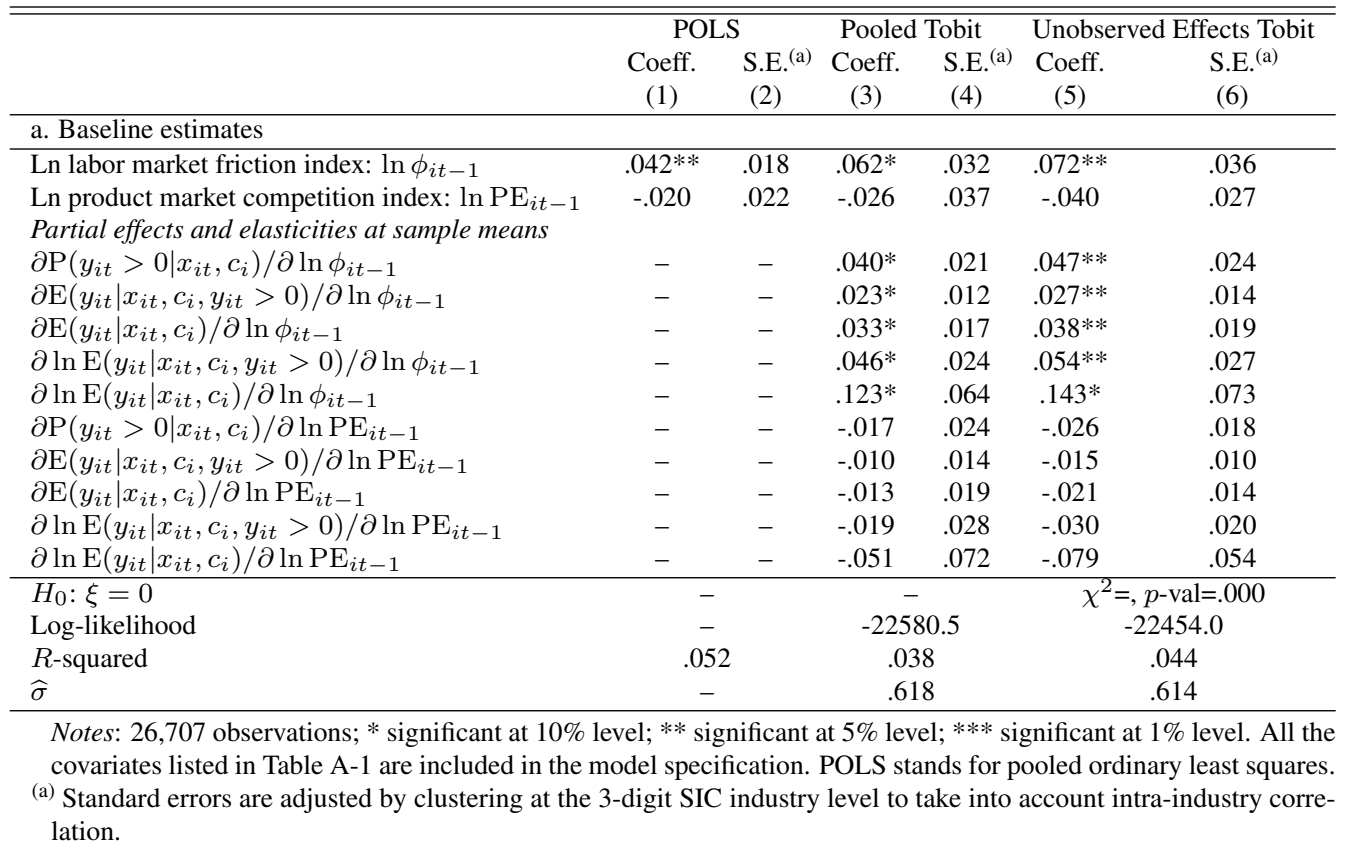

\subsection{Sensitivity analysis}

To investigate the robustness of our parameter estimates we perform a number of sensitivity analyses, starting with a investigation of strict exogeneity of the market imperfections indicators. The estimation method we have used so far hinges on the strict exogeneity of the market indexes conditional on firm unobserved effects. This is a strong assumption, which rules out the possibility that a shock in training for firm $i$ in period $t$ might have an effect on the market structure in terms of firms' monopsony power or of firms' product market power. We test whether this situation is empirically relevant here by using the strict exogeneity test proposed by Wooldridge (2002, § 15.8.2) for discrete response panel data models. We add the contemporaneous values of the market imperfection indexes as additional regressors. Under the null hypothesis, the contemporaneous market imperfection indexes should be insignificant. Fully robust significance tests return a $p$-value equal to 0.712 for the significance of the contemporaneous labor market friction index and to 0.216 for the significance of the contemporaneous product market power index. ${ }^{11}$ Thereby, we cannot confidently reject the null hypothesis, supporting the strict exogeneity assumption.

Our second sensitivity analysis concerns the parametric restrictions of the model defined in (2) and (3). Parametric and semiparametric methods can be used to deal with the presence of the

\footnotetext{
${ }^{11}$ A fully robust joint significance test returns a $p$-value equal to 0.291.
} 
fixed effects $u_{i}$ in this non-linear framework. ${ }^{12}$ In the benchmark model, we used a Mundlak (1978) version of Chamberlain's (1984) approach: a parametric approach that imposes some restrictions on the distribution of $c_{i}$, which does not exclude dependence between $x_{i}$ and $c_{i}$. The advantage of this model is that it allows estimation of the parameters and of a set of other quantities of interest from the policy perspective, like marginal effects of covariates. However, there is no guarantee that the parametric restrictions hold. The main goal of semiparametric methods is to construct estimators under more general assumptions. We test now the robustness of the results to too strict parametric assumptions by implementing the semiparametric estimator for censored regression panel data models with fixed effects introduced by Honore (1992).

Take $t=1,2$ and define $\Delta x_{i}=x_{i 2}-x_{i 1}$. If $u_{i 1}$ and $u_{i 2}$ are $i i d$ conditional on $\left(x_{i 1}, x_{i 2}, c_{i}\right)$, $\left(y_{i 1}^{*}, y_{i 2}^{*}\right) \mid\left(x_{i 1}, x_{i 2}\right)$ is symmetric around the $45^{\circ}$-line through $\left(\Delta x_{i}^{\prime} \beta, 0\right)$. Honore noticed that the symmetry is not affected by the censoring, so it holds also for the observed variables $\left(y_{i 1}, y_{i 2}\right)$. The symmetry can be exploited to derive orthogonality conditions that must hold at the true parameter values without the need for assumptions on the distributions of the fixed effects or error terms. Honoré derives two moments restrictions on the basis of which he proposes two estimators. We use Honoré's second estimator, since the corresponding objective function has some smoothness properties that makes it straightforward estimation and inference. ${ }^{13}$ The vector of coefficients $\beta$ enters the objective function through $\left(x_{i 2}-x_{i 1}\right)^{\prime} \beta$, meaning that estimation hinges on time-variation: the coefficients of time-invariant variables are not identified. Moreover, the estimation of the marginal effects is not addressed in Honoré.

Table 4 displays Honoré estimation results of the coefficients of market imperfections. Columns (1) and (2) report the estimation results of the model that comprises all the timevarying variables used in the benchmark specification. In columns (3) and (4), covariates that are jointly and separately insignificant are removed from the set of regressors. ${ }^{14}$ The estimates for the friction indicator are similar to those in the benchmark model. The estimates for the product market competition index display instead an unexpected positive sign. However, as in the benchmark model, they are not significantly different zero. This evidence assesses the robustness of the results obtained under stricter parametric assumptions on the fixed effects and error terms.

As a third sensitivity analysis we estimate a model in which the job offer arrival rate $\lambda$, the job destruction rate $\delta$, and their squares are included separately among the regressors, instead of only by way of $\ln \phi$ and definition in (1). Both $\lambda$ and $\delta$ can be viewed as separate measures

\footnotetext{
${ }^{12}$ See Charlier et al. (2000) for a comparison between parametric and semiparametric estimators for censored regression panel data model with fixed effects.

${ }^{13}$ There are other strategies to construct more efficient estimators than this Honoré estimator. See Charlier et al. (2000). It is beyond the scope of this subsection to implement the most efficient estimator. It is aimed at testing the robustness of the benchmark model to parametric assumptions. Thereby, we will limit this sensitivity analysis to Honoré's estimator with $t=2004,2005$.

${ }^{14}$ The variables that are jointly and separately insignificant are value added, investments in machine and equipment, $\mathrm{R} \& \mathrm{D}$, temporary work agency costs, advertising costs, communication costs, patent costs, and the time dummy.
} 
Table 4: Sensitivity of the results to parametric assumptions: Honoré estimates

\begin{tabular}{lcccc}
\hline \hline & \multicolumn{2}{c}{ Full set of covariates } & \multicolumn{2}{c}{ Only jointly significant covariates } \\
& Coeff. & S.E. & Coeff. & S.E. \\
& $(1)$ & $(2)$ & $(3)$ & $(4)$ \\
\hline Ln labor market friction index: $\ln \phi_{i t-1}$ & .036 & .031 & $.055^{*}$ & .033 \\
Ln product market competition index: $\mathrm{PE}_{i t-1}$ & .012 & .016 & .014 & .016 \\
\hline
\end{tabular}

Notes: 10,936 observations; fraction of censored observations $=0.590 ; *$ significant at $10 \%$ level.

Table 5: Sensitivity analysis firm-sponsored training: alternative measures of market imperfections; unobserved effects tobit model

\begin{tabular}{lcc}
\hline \hline & & \\
a. Labor market imperfections & Coeff. & S.E. ${ }^{(a)}$ \\
\hline Job offer arrival rate: $\lambda_{i t-1}$ & $-5.083^{* * *}$ & 1.903 \\
$\lambda_{i t-1}^{2}$ & $32.909^{* *}$ & 12.961 \\
Job destruction rate: $\delta_{i t-1}$ & $-64.687^{* *}$ & 31.051 \\
$\delta_{i t-1}^{2}$ & 2477.320 & 1525.278 \\
Elasticities at sample means & & \\
$\partial \ln \mathrm{E}\left(y_{i t} \mid x_{i t}, c_{i}, y_{i t}>0\right) / \partial \ln \lambda_{i t-1}$ & $-.033^{* * *}$ & .012 \\
$\partial \ln \mathrm{E}\left(y_{i t} \mid x_{i t}, c_{i}, y_{i t}>0\right) / \partial \ln \delta_{i t-1}$ & $-.247^{* *}$ & .123 \\
$\partial \ln \mathrm{E}\left(y_{i t} \mid x_{i t}, c_{i}\right) / \partial \ln \lambda_{i t-1}$ & $-.087^{* * *}$ & .032 \\
$\partial \ln \mathrm{E}\left(y_{i t} \mid x_{i t}, c_{i}\right) / \partial \ln \delta_{i t-1}$ & $-.654^{* *}$ & .323 \\
\hline$H_{0}: \xi=0$ & $\chi_{18}^{2}=272.3, p$-val=.000 \\
Log-likelihood & \multicolumn{2}{c}{-22436.6} \\
$R$-squared & \multicolumn{2}{c}{.644} \\
$\widehat{\sigma}$ & \multicolumn{2}{c}{.614} \\
\hline \hline
\end{tabular}

b. Product market imperfections - PCM

\begin{tabular}{lcc}
\hline $\ln \mathrm{PCM}_{i t-1}$ & .077 & .055 \\
Elasticities at sample means & & \\
$\partial \ln \mathrm{E}\left(y_{i t} \mid x_{i t}, c_{i}, y_{i t}>0\right) / \partial \ln \mathrm{PCM}_{i t-1}$ & .058 & .043 \\
$\partial \ln \mathrm{E}\left(y_{i t} \mid x_{i t}, c_{i}\right) / \partial \ln \mathrm{PCM}_{i t-1}$ & .154 & .113 \\
\hline$H_{0}: \xi=0$ & $\chi_{15}^{2}=203.3, p$-val=.000 \\
Log-likelihood & \multicolumn{2}{c}{-22446.8} \\
$R$-squared & \multicolumn{2}{c}{.044} \\
$\widehat{\sigma}$ & .614 \\
\hline
\end{tabular}

Notes: 26,707 observations; * significant at $10 \%$ level; $* *$ significant at $5 \%$ level; *** significant at $1 \%$ level. All the covariates listed in Table A-1 are included in the model specification. Standard errors are adjusted by clustering at the 3-digit SIC industry level to take into account intra-industry correlation. 
of labor market frictions. The former is the rate at which new job opportunities are received by employees and therefore could capture mobility costs, vacancy availability, firm's propensity to poach employees. The latter is the rate at which job destructions occur and is therefore linked to the state of the economy and to the labor market institutions on dismissals and firing costs. The top part of Table 5 reports the estimation results. It is noted that the estimated effects have the expected sign: an increase either in the job offer arrival rate or in the job destruction rate has a negative effect with decreasing returns, ceteris paribus, on firm-sponsored training. Even if the coefficient of the squared job offer arrival rate is significantly positive, note that only less than one percent of the observations would lie on the increasing part of the training-job offer arrival rate quadratic function. For the average firm, a $10 \%$ increase in the job offer arrival rate generates a $0.9 \%$ reduction in firm-sponsored training and a $10 \%$ increase in the job destruction rate generates a $6.5 \%$ reduction in firm-sponsored training. Most of the effect of labor market frictions on training that we saw in Section 5 seems therefore to derive from the job destruction rate rather than the job offer arrival rate. ${ }^{15}$

In a fourth robustness check, we investigated how sensitive our main results are to alternative specifications of product market competition. We replicate the analysis of the benchmark model by substituting the price cost margin (PCM) for the PE in the training equation. ${ }^{16}$ The lower part of Table 5 shows that the PCM has indeed a positive effect on firm-sponsored training. However, the estimated coefficient is not significantly different from zero, which is very much in line with those obtained using PE as index of product market competition. In this application the chosen method to measure product market competition does not affect the conclusions.

Finally, we check the sensitivity analysis of our results to outliers and to too restrictive functional forms of the market imperfection indexes. In the former check, we replicated the analysis by dropping from the sample firms belonging to the sector of iron and steel. In this sector PE is indeed much higher (look at panel b of Figure 1) and it might be that the corresponding observations are influential in determining the results. We found that the results are not sensitive to outlying observations. In the latter check, we changed the model specification and instead of log-linear functional forms for the market imperfection indexes we adopted log-quadratic functional forms or continuous spline functional forms (with knots at several percentiles of the market imperfection indexes). Once again, we found results that are very much in line with those of the benchmark model.

\footnotetext{
${ }^{15}$ We also used a quadratic specification of the relation between marginal costs and marginal profits in model (B-4). Then the PE varies with marginal costs. The parameter estimates relating PE with firm-sponsored training were in line with those of the benchmark model.

${ }^{16}$ The PCM as a market measure of competition is usually calculated as market aggregate profits over market aggregate revenues. A large PCM indicates large opportunities of profits and, therefore, a highly concentrated industry. The closer the PCM is to zero, the more competitive the industry.
} 


\subsection{The quantitative importance of market imperfections}

This subsection assesses the quantitative importance of labor market imperfections as determinants of firms' expenditure on training. This is done by estimating average partial effects (APEs) induced by changes in the magnitude of the labor market imperfection indicators: we compare predicted and counterfactual training expenditures at the sample means of the covariates as suggested by Wooldridge (2002, § 16.8.2).

On the basis of the estimation results of the benchmark model, we estimate the following APEs:

i) The average change in expenditures and in the fraction of firms investing in training if all the sectors were characterized by low labor market frictions. We pick $\phi$ to be equal to the minimum observed over the sample period. ${ }^{17}$ Thereby, we mimic the firm-sponsored training implications of an economy-wide increase in labor market flexibility to the level of the most flexible labor market. It is found that an economy-wide move to a very flexible labor market would reduce firms' expenditures in training by $36 \%$ ( $€ 96$ per unit of labor) and the fraction of firms investing in training by $13.4 \%$.

ii) The average change in expenditures and in the fraction of firms investing in training if, in every sector, there were one more job offer per unit of job destruction. In this case expenditure on training decreases by $4.8 \%$ ( $€ 12.9$ per unit of labor) and the fraction of firms investing in training decreases by $1.6 \%$

iii) The average change in expenditures and in the fraction of firms investing in training if the labor market frictions decreased by one standard deviation. Expenditure in training would decrease by $5.4 \%$ ( $€ 14.6$ per unit of labor) and the fraction of firms investing in training would decrease by $1.8 \%$.

\section{Conclusions}

Investments in training of workers are important for individual firms because they stimulate productivity of workers and competitiveness of firms. The extent to which training of workers is important differs between firms. Some firms may chose to hire less skilled workers and invest in training of these workers while other firms prefer to hire more skilled workers and provide less training. The importance of workers' training goes beyond individual firms as training may facilitate sectoral adjustment and stimulate growth nationwide. Investment in training may be affected by market imperfections. Indeed, recent human capital theories predict that labor market frictions and product market competition influence firm-sponsored training.

Our paper investigates how market imperfections affect firms' propensity to sponsor training. We use Dutch data covering the census population of manufacturing firms with more than

\footnotetext{
${ }^{17}$ The lowest level of labor market frictions is registered in 2001 in the manufacture of games and toys.
} 
20 employees and the census population of workers. We first compute two indexes of labor market friction and product market competition at 3-digit SIC industry level. Then, we recover the causal effect of both type of market imperfections on firm-sponsored training. We find that a decrease in labor market frictions significantly reduces firms' training expenditures. From a sensitivity analysis it appears that this is largely driven by the effect of a change in job destruction. Clearly, if the job destruction rate goes up investments in firm-specific training go down because of the reduction in the period over which investments are paid-back. Instead, product market competition does not have an effect on firm-sponsored training. From this we conclude that increasing competition through international integration and globalization does not pose a threat to investments in on-the-job training. An increase in labor market flexibility may reduce incentives of firms to invest in training, but the magnitude of this effect is small.

\section{Appendix A Details on the data}

The PS data provide detailed and disaggregated information on turnover, value-added, personnel costs, investments, number of employees, industry classification, and other firms and industry characteristics. Table A-1 displays summary statistics of the key variables used in the analysis. The dependent variable is the costs sustained by the firm for studying and training of their employees per unit of labor. ${ }^{18}$ A large fraction of firms do not sponsor at all training and, overall, the fraction of observations with some training is equal to $63.7 \%$. The important mass of observations at zero training costs calls for econometric models properly accounting for the presence of corner solution outcomes (see Section 5). The investment in training per unit of labor is equal to $€ 220$ on average and ranges to a maximum of $€ 25,350$. The average training costs per unit of labor conditional on sponsoring training is instead equal to $€ 345$. The average firm size is about 104 employees for an average wage cost of more than $€ 4$ million. More than half of the observations in the sample are concentrated in 4 sectors: manufacture of food and beverage products (SIC-15), of fabricated metal products (SIC-28), of machinery and equipment (SIC-29), and publishing, printing and reproduction of recorded media (SIC22). The others are scattered over the other 2-digit manufacturing industries. The rest of the listed variables (e.g. $R \& D$, advertising costs, communication costs, and costs of patents) enter the specification of the econometric models and try to capture firm heterogeneity, both timeconstant and time-varying. They are aimed at approximating heterogeneity in firm organization structures and manager qualities, so as to remove spurious correlation between the error term and the market imperfections industry indicators.

\footnotetext{
${ }^{18}$ The costs for studying and training are normalized by the number of full time equivalent employees.
} 
Table A-1: Sample Characteristics of Manufacturing Firms

\begin{tabular}{|c|c|c|c|c|}
\hline & Mean & Std. Dev. & Min. & Max. \\
\hline Fraction of firms sponsoring training & 0.635 & 0.481 & 0 & 1 \\
\hline Expenditure on training per unit of labour $(€ 1,000)$ & 0.220 & 0.470 & 0.000 & 25.350 \\
\hline $\begin{array}{l}\text { Expenditure on training per unit of labour }(€ 1,000) \\
\text { conditional on sponsoring training }\end{array}$ & 0.345 & 0.550 & 0.004 & 25.350 \\
\hline Number of employees & 103.80 & 476.34 & 20 & 32076 \\
\hline Wage cost $(€ 1,000)$ & 4057.0 & 21097.9 & 3.000 & 1424916 \\
\hline Cost of temporary work agencies $(€ 1,000)$ & 474.41 & 2469.00 & 0 & 159014 \\
\hline Value added $(€ 1,000,000)$ & 8.410 & 48.721 & -1926.90 & 2302.30 \\
\hline Operating income: total net sales $(1,000,000 €)$ & 36.480 & 24.288 & 0.200 & 12801.68 \\
\hline Received refunds and grants $(€ 1,000)$ & 131.56 & 2425.31 & -79 & 163384 \\
\hline Costs of buildings and lands $(€ 1,000)$ & 482.18 & 2732.56 & 0 & 165342 \\
\hline Costs of equipment and machines $(€ 1,000)$ & 625.90 & 4497.70 & 0 & 384028 \\
\hline $\mathrm{R} \& \mathrm{D}(€ 1,000)$ & 371.33 & 18207.9 & 0 & 1860300 \\
\hline Advertising costs $(€ 1,000)$ & 319.35 & 2428.97 & 0 & 98603 \\
\hline Communication costs $(€ 1,000)$ & 86.15 & 471.99 & 0 & 30426 \\
\hline Costs of patent and licensing rights $(€ 1,000)$ & 208.37 & 4124.28 & 0 & 244369 \\
\hline Cost of energy $(€ 1,000)$ & 798.15 & 9193.62 & 0 & 436737 \\
\hline \multicolumn{5}{|l|}{ Standard Industrial Classification 1993 (2-digit) } \\
\hline SIC-15 & 0.133 & 0.340 & 0 & 1 \\
\hline SIC-16 & 0.002 & 0.046 & 0 & 1 \\
\hline SIC-17 & 0.027 & 0.163 & 0 & 1 \\
\hline SIC-18 & 0.006 & 0.080 & 0 & 1 \\
\hline SIC-19 & 0.004 & 0.061 & 0 & 1 \\
\hline SIC-20 & 0.034 & 0.182 & 0 & 1 \\
\hline SIC-21 & 0.033 & 0.178 & 0 & 1 \\
\hline SIC-22 & 0.099 & 0.299 & 0 & 1 \\
\hline SIC-23 & 0.003 & 0.054 & 0 & 1 \\
\hline SIC-24 & 0.054 & 0.227 & 0 & 1 \\
\hline SIC-25 & 0.056 & 0.230 & 0 & 1 \\
\hline SIC-26 & 0.043 & 0.202 & 0 & 1 \\
\hline SIC-27 & 0.014 & 0.117 & 0 & 1 \\
\hline SIC-28 & 0.172 & 0.377 & 0 & 1 \\
\hline SIC-29 & 0.147 & 0.354 & 0 & 1 \\
\hline SIC-30 & 0.003 & 0.057 & 0 & 1 \\
\hline SIC-31 & 0.024 & 0.155 & 0 & 1 \\
\hline SIC-32 & 0.008 & 0.088 & 0 & 1 \\
\hline SIC-33 & 0.030 & 0.170 & 0 & 1 \\
\hline SIC-34 & 0.026 & 0.158 & 0 & 1 \\
\hline SIC-35 & 0.026 & 0.160 & 0 & 1 \\
\hline SIC-36 & 0.055 & 0.227 & 0 & 1 \\
\hline \multicolumn{5}{|l|}{ Time dummies } \\
\hline 2001 & 0.204 & 0.403 & 0 & 1 \\
\hline 2002 & 0.150 & 0.357 & 0 & 1 \\
\hline 2003 & 0.211 & 0.408 & 0 & 1 \\
\hline 2004 & 0.214 & 0.410 & 0 & 1 \\
\hline 2005 & 0.221 & 0.415 & 0 & 1 \\
\hline Observations & & & & 26707 \\
\hline
\end{tabular}

Notes: Pooled data for the PS waves (2001-2005).

(a) Training per unit of labor is defined as the expenditures on training per full-time equivalent employee. 


\section{Appendix B Measuring market imperfections}

\section{B-1 Labor market frictions}

The labor market friction index is estimated by using Ridder and van den Berg's (2003) conditional inference approach. We exploit the information contained in the waves of the SBB Jobs data on the joint distribution of elapsed job durations and wages among currently employed workers. ${ }^{19}$

Consider a standard partial on-the-job search model (e.g. Mortensen, 1986) where firms do not post wages under the reservation wage. In steady-state, the following relation can be derived by equating the flow into and out the stock of workers earning a wage equal to or smaller than $w:^{20}$

$$
G(w)=\frac{F(w)}{1+\frac{\lambda}{\delta}[1-F(w)]},
$$

where $G$ is the cross-section cdf of wages and $F$ is the underlining cdf of offered wages. Within each market and for each year in the time window 2000-2005, we non-parametrically estimate $G(w)$ by taking the empirical cdf from the data:

$$
\widehat{G}(w)=\frac{1}{N} \sum_{i=1}^{N} 1\left(w_{i} \leq w\right)
$$

where $1(\cdot)$ is the indicator function and $N$ is the total number of employees in the market and year under consideration. In such framework, the job exit rate is $\lambda[1-F(w)]+\delta$ and the contribution to the likelihood function of individual $i$ with job tenure $t_{i}$ given the wage $w_{i}$ is

$$
\mathscr{L}_{i}=\left\{\delta+\lambda\left[1-F\left(w_{i}\right)\right]\right\} \exp \left\{-t_{i}\left[\delta+\lambda\left[1-F\left(w_{i}\right)\right]\right\}\right.
$$

Exploiting relation (B-1), the likelihood function can be expressed in terms of $\widehat{G}, \lambda$, and $\delta$. Estimates of $\lambda$ and $\delta$ are therefore obtained by maximizing the following log-likelihood function:

$$
\ln \mathscr{L}(\lambda, \delta)=\sum_{i}\left\{\ln (\delta+\lambda)-\ln \left[1+\frac{\lambda}{\delta} \widehat{G}\left(w_{i}\right)\right]-t_{i}\left[\frac{\delta+\lambda}{1+\frac{\lambda}{\delta} \widehat{G}\left(w_{i}\right)}\right]\right\} .
$$

\footnotetext{
${ }^{19}$ Ridder and van den Berg (2003) also propose an unconditional indicator of labor market frictions, which is more robust from the theoretical viewpoint and focuses on the duration dependence pattern of the job exit rate due to unobserved heterogeneity. However, this unconditional indicator is less robust from an econometric point of view.

${ }^{20}$ See, e.g., Burdett and Mortensen (1998) for the derivation of equation (B-1) within an equilibrium search model with on-the-job search, random matching, and wage posting.
} 


\section{B-2 Product market competition}

The product market competition index used in this paper is the PE. The PE is more robust as an indicator for product market competition than for example the PCM. ${ }^{21}$ Consider the case, for instance, when firms in a given sector start behaving more aggressively. This might result in inefficient firms being forced out of the market and in a bigger market share for the survivors. In such a hypothetical situation characterized by an increased competition due to a more aggressive firm conduct, the PCM would wrongly indicate less intense competition. The PE avoids such pitfalls since it is not based on profits and costs levels. Rather, it looks at the marginal variation in profits caused by a marginal variation in costs per unit of output. If this relation becomes steeper over time, competition has become more intense. The underlining idea, based on the theoretical work in Boone (2008), is that in more competitive markets firms are punished more harshly in terms of profits for being inefficient.

The computation of the PE for each 3-digit SIC industry follows Boone et al. (2009) and is based on the estimation by ordinary least squares (OLS) of the following equation

$$
\ln \left(\pi_{i t}\right)=\alpha_{i}+\alpha_{t}-\beta_{t} \ln \left(\frac{c_{i t}}{r_{i t}}\right)+\varepsilon_{i t},
$$

where $\pi_{i t}, c_{i t}$, and $r_{i t}$ are respectively profits, costs, and revenues of firm $i$ at time $t, \alpha_{i}$ and $\alpha_{t}$ are firm and time fixed effects, $\varepsilon_{i t}$ is the error term. The coefficient $\beta_{t}$ is the percentage increase in profits due to a percentage increase of costs per unit of revenues, $c_{i t} / r_{i t}$, which is our measure of product market competition. ${ }^{22}$ Boone et al. (2009) show under which assumptions an increase (decrease) of $\beta_{t}$ over time can be safely interpreted as more (less) intense competition in the corresponding industry. It is precisely the time-variation of this index that will convey information to identify the impact of PE on firm-sponsored training in an unobserved effects econometric framework.

\section{References}

Acemoglu, D. (1997) 'Training and innovation in an imperfect labour market.' Review of Economic Studies 64(3), 445-464

Acemoglu, D., and J.S. Pischke (1998) 'Why do firms train? Theory and evidence.' Quarterly Journal of Economics 113(1), 79-119

_ (1999a) 'Beyond Becker: Training in imperfect labour markets.' Economic Journal 109(453), F112-F142

_ (1999b) 'The structure of wages and investment in general training.' Journal of Political Economy 107(3), 539572

\footnotetext{
${ }^{21}$ See Boone et al. (2009) for a comparison between PE and more standard measures of product market competition.

${ }^{22}$ Since we have no data on prices, we cannot derive price-based cost measures like the cost per unit of output and, following Boone et al. (2009), we stick to the cost per unit of revenue.
} 
Autor, D.H. (2001) 'Why do temporary help firms provide free general skills training?' Quarterly Journal of Economics 116(4), 1409-1448

Barron, J.M., M.C. Berger, and D.A. Black (1999) 'Do workers pay for on-the-job training?' Journal of Human Resources 34(2), 235-252

Bassanini, A., and G. Brunello (2008) 'Is training more frequent when the wage premium is smaller? Evidence from the European Community Household Panel.' Labour Economics 15(2), 272-290

_ (2010) 'Barriers to entry, deregulation and workplace training: A theoretical model with evidence from Europe.' CESifo Working Paper No. 2945, Munich

Becker, G.S. (1962) 'Investment in human capital: A theoretical analysis.' Journal of Political Economy 70(5), 949

_ (1964) Human Capital: A Theoretical and Empirical Analysis, with Special Reference to Education (New York: Columbia University Press)

Bontemps, C., J.M. Robin, and G.J. van den Berg (2000) 'Equilibrium search with continuous productivity dispersion: Theory and nonparametric estimation.' International Economic Review 41(2), 305-358

Boone, J. (2008) 'A new way to measure competition.' Economic Journal 118(531), 1245-1261

Boone, J., J.C. van Ours, and H. van der Wiel (2009) 'When is the price cost margin a safe way to measure changes in competition?' Tilburg University, mimeo

Booth, A.L., and M.L. Bryan (2005) 'Testing some predictions of human capital theory: New training evidence from Britain.' Review of Economics and Statistics 87(3), 391-394

Brunello, G., and F. Gambarotto (2007) 'Do spatial agglomeration and local labor market competition affect employer-provided training? Evidence from the UK.' Regional Science and Urban Economics 37(1), 1-21

Brunello, G., and M. De Paola (2008) 'Training and economic density: Some evidence from Italian provinces.' Labour Economics 15(1), 118-140

Burdett, K., and D.T. Mortensen (1998) 'Wage differentials, employer size, and unemployment.' International Economic Review 39(2), 257-273

Chamberlain, G. (1984) 'Panel data.' In Handbook of Econometrics, ed. Z. Grichiles and M.D. Intriligator (Amsterdam: North Holland) chapter 22, pp. 1248-1318

Chang, C., and Y. Wang (1995) 'A framework for understanding differences in labor turnover and human capital investment.' Journal of Economic Behavior and Organization 28(1), 91-105

_ (1996) 'Human capital investment under asymmetric information: The Pigovian conjecture revisited.' Journal of Labor Economics 14(3), 505-519

Charlier, E., B. Melenberg, and A. van Soest (2000) 'Estimation of a censored regression panel data model using conditional moment restrictions efficiently.' Journal of Econometrics 95(1), 25-56

Gerfin, M. (2004) 'Firm-sponsored general training in frictional labour markets: An empirical analysis for Switzerland.' IZA Discussion Paper No. 1077, Bonn

Gersbach, H., and A. Schmutzler (2006) 'A product market theory of industry-specific training.' SOI Working Paper No. 610, Zurich 
Görlitz, K., and J. Stiebale (2008) 'Does product market competition decrease employers' training investments? Evidence from German establishment panel data.' Ruhr Economic Paper No. 41, Essen

Green, F., A. Felstead, K. Mayhew, and A. Pack (2000) 'The impact of training on labour mobility: Individual and firm-level evidence from Britain.' British Journal of Industrial Relations 38(2), 261-275

Harhoff, D., and T.J. Kane (1997) 'Is the German apprenticeship system a panacea for the U.S. labor market?' Journal of Population Economics 10(2), 171-196

Honoré, B.E. (1992) 'Trimmed lad and least squares estimation of truncated and censored regression models with fixed effects.' Econometrica 60(3), 533-565

Katz, E., and A. Ziderman (1990) 'Investment in general training: The role of information and labour mobility.' Economic Journal 100(403), 1147-1158

Leuven, E. (2005) 'The economics of private sector training: A survey of the literature.' Journal of Economic Surveys 19(1), 91-111

Loewenstein, M.A., and J.R. Spletzer (1998) 'Dividing the costs and returns to general training.' Journal of Labor Economics 16(1), 142-171

_ (1999) 'General and specific training: Evidence and implications.' Journal of Human Resources 34(4), 710-733

Manning, A. (2003) Monopsony in Motion: Imperfect Competition in Labor Markets (Princeton: Princeton University Press)

Mortensen, D.T. (1986) 'Job search and labor market analysis.' In Handbook of Labor Economics Vol. 2, ed. O. Ashenfelter and R. Layard (Amsterdam: North-Holland) chapter 15, pp. 849-919

Muehlemann, S. (2008) 'Firm-sponsored training and poaching externalities in regional labor markets.' University of Berne, mimeo. http://www.educationeconomics.uzh.ch/1Aboutus-2/Projekt1-1/Muehlemann.pdf

Muehlemann, S., and S.C. Wolter (2007) 'Regional effects on employer-provided training: Evidence from apprenticeship training in Switzerland.' Journal for Labour Market Research 40(2/3), 135-147

Mundlak, Y. (1978) 'On the pooling of time series and cross section data.' Econometrica 46(1), 69-85

Ridder, G., and G.J. van den Berg (2003) 'Measuring labor market frictions: A cross-country comparison.' Journal of the European Economic Association 1(1), 224-244

Shintoyo, N. (2008) 'Creation of jobs and firm-sponsored training in a matching model of unemployment.' Journal of Economics 93(2), 145-176

Stevens, M. (2001) 'Should firms be required to pay for vocational training?' Economic Journal 111(473), 485505

van den Berg, G.J., and A. van Vuuren (2005) 'The effects of search frictions on wages.' Tinbergen Institute Discussion Paper No. 2006-077/3

Wooldridge, J.M. (2002) Econometric Analysis of Cross Section and Panel Data (Cambridge: MIT Press) 